\title{
Iron absorption from a malted cocoa drink fortified with ferric orthophosphate using the stable isotope ${ }^{58} \mathrm{Fe}$ as an extrinsic label
}

\author{
BY SUSAN J. FAIR WEATHER-TAIT \\ ARC Food Research Institute, Colney Lane, Norwich NR4 7UA
}

AND MARGARET J. MINSKI

The Reactor Centre, Imperial College, Silwood Park, Sunninghill, Ascot, Berks SL5 7PY

AND D. P. RICHARDSON

The Lord Zuckerman Research Centre, Cadbury Schweppes Group Research, The University, Whiteknights, Reading, Berks RG6 2LA

(Received 4 January 1983 - Accepted 18 February 1983)

1.The potential use of an extrinsic label to measure iron absorption from a ferric orthophosphate-fortified malted cocoa drink was examined by measuring the solubility of the $\mathrm{FePO}_{4}$ in $0.1 \mathrm{~m}$-hydrochloric acid.

2. The validity of using the stable isotope ${ }^{58} \mathrm{Fe}$ as an extrinsic label was tested by comparing $\mathrm{Fe}$ absorption by rats from wheat flour extrinsically-labelled with ${ }^{58} \mathrm{Fe}$ or ${ }^{59} \mathrm{Fe}$.

3. Fe absorption from a malted cocoa drink ( $20 \mathrm{~g}$ powder made up with hot water) fortified with $\mathrm{FePO}_{4}$ $\left(0.5 \mathrm{mg} \mathrm{Fe} / \mathrm{g}\right.$ powder) was measured in human subjects using ${ }^{58} \mathrm{Fe}$ as an extrinsic label. Absorption was calculated by measuring unabsorbed ${ }^{58} \mathrm{Fe}$ in faeces. Absorptions of $\mathrm{Fe}$ from the drink fortified with either $\mathrm{FePO}_{4}$ or ferrous sulphate were compared. The effect of the addition of ascorbic acid to the drink ( $1 \mathrm{mg} / \mathrm{g}$ powder) on $\mathrm{Fe}$ availability was also examined.

4. The effect of fasting on $\mathrm{Fe}$ absorption from the drink was determined in rats by giving the drink to fasting animals or shortly after they had consumed a small meal.

5. The $\mathrm{FePO}_{4}$ was totally soluble in $0 \cdot 1 \mathrm{M}-\mathrm{HCl}$ and there were no differences in absorption between ${ }^{58} \mathrm{Fe}$ - and ${ }^{59} \mathrm{Fe}$-labelled wheat flour. In the human experiment the proportion of $\mathrm{Fe}$ absorbed from the drink plus $\mathrm{FePO}_{4}$ and ascorbic acid was (mean with sE) $0.25(0.02)$, from the drink plus $\mathrm{FePO}_{4} 0.24(0.02)$ and from the drink plus $\mathrm{FeSO}_{4} 0 \cdot 23(0 \cdot 03)$. Fasting had a significant effect on $\mathrm{Fe}$ availability; rats given the drink shortly after a small meal absorbed less than half as much Fe as those given the drink on a fasted stomach.

6. It was concluded that the $\mathrm{FePO}_{4}$ used to fortify the malted cocoa drink was as well absorbed as $\mathrm{FeSO}_{4}$ but that the high levels of absorption were a reflection of the fasting condition of the subjects. The level of ascorbic acid was not great enough to enhance the availability of the $\mathrm{FePO}_{4}$ any further.

Ferric orthophosphate is often used as the iron source in food products fortified with Fe. It is a relatively unreactive salt and therefore does not cause problems of discolouration, rancidity or unpleasant taste. However, it is commonly believed to be poorly absorbed compared to the highly-available Fe salt ferrous sulphate (Rees \& Monsen, 1973). Since ascorbic acid is known to enhance Fe absorption, investigations were carried out on the effect of ascorbic acid on Fe absorption from $\mathrm{FePO}_{4}$ which had been added to a malted cocoa drink.

The main objective of this work was to measure Fe absorption in human subjects from a malted cocoa drink fortified with $\mathrm{FePO}_{4}$ with and without ascorbic acid, and to compare absorption with that from $\mathrm{FeSO}_{4}$. The method used was extrinsic labelling of the $\mathrm{Fe}$ using the stable isotope ${ }^{58} \mathrm{Fe}$ followed by faecal monitoring to measure unabsorbed Fe. Before this was undertaken the use of ${ }^{58} \mathrm{Fe}$ to extrinsically-label the $\mathrm{FePO}_{4}$ was validated. 


\section{MATERIALS AND METHODS}

The malted cocoa drink contained malt extract, sugar, dried glucose syrup, fat reduced cocoa, dried skimmed milk, dried egg, sodium carbonate, salt and flavourings. The ingredients and the added nutrients (where applicable) were thoroughly mixed and transferred to trays. The mixture was then dried for approximately $4 \mathrm{~h}$ at $70^{\circ}$ in a vacuum oven, cooked, granulated and packed in sealed cans.

\section{Solubility of $\mathrm{FePO}_{4}$}

The validity of the 'extrinsic tag' method has been extensively tested and it has been found that it can only be used when there is complete isotopic exchange between the food $\mathrm{Fe}$ and added tracer. These must both be sufficiently soluble to effect complete isotopic exchange before absorption commences. Different preparations of $\mathrm{FePO}_{4}$ exhibit different solubilities and hence different levels of bioavailability (Harrison et al. 1976). The solubility of the $\mathrm{FePO}_{4}$ (Albright \& Wilson, Warley, West Midlands) used to fortify the malted cocoa drink was measured by mechanically shaking $20 \mathrm{mg}$ of the Fe salt with $100 \mathrm{ml} 0 \cdot 1 \mathrm{M}$ hydrochloric acid and quantitatively collecting any residue on filter paper as described by Pla et al. (1973). Amounts $(1 \mathrm{~g})$ of the three samples of powdered drink were also tested for Fe solubility at $37^{\circ}$ but in this case the filtrate was analysed for Fe by atomic absorption spectrophotometry (AAS) in order to measure solubility.

\section{Comparison between ${ }^{58} \mathrm{Fe}$ and ${ }^{59} \mathrm{Fe}$ used as extrinsic labels}

Although the valid use of the stable isotope ${ }^{58} \mathrm{Fe}$ as an extrinsic label has already been described (Janghorbani et al. 1980) it was decided to confirm that it could be used to measure $\mathrm{Fe}$ absorption from the malted cocoa drink.

Twenty-four young male Wistar rats were given a control semi-synthetic diet, the formulation of which is shown in Table 1, and trained to meal-feed for 1 week. After an overnight fast they were given $3 \mathrm{~g}$ whole-wheat flour (containing $140 \mu \mathrm{g} \mathrm{Fe}$ ) made to a paste with distilled water and labelled with $58 \mu \mathrm{g}{ }^{58} \mathrm{Fe}(88 \mu \mathrm{g} \mathrm{Fe})$ or $1 \mu \mathrm{Ci}{ }^{59} \mathrm{Fe}$ (ferric chloride; Amersham International, Bucks) containing negligible $\mathrm{Fe}$. The ${ }^{58} \mathrm{Fe}$ was prepared from ferric oxide enriched to $66 \%$ (AERE, Harwell) dissolved in $0.1 \mathrm{M}-\mathrm{HCl}$, and contributed a significant amount of $\mathrm{Fe}$. Therefore the same amount of $\mathrm{Fe}$ as $\mathrm{FeCl}_{3}$ in $0.1 \mathrm{M}-\mathrm{HCl}$ was added to the ${ }^{50} \mathrm{Fe}$-labelled flour. At $5 \mathrm{~h}$ after the meal the rats were allowed access to the control diet. Faeces were collected daily and those from the ${ }^{59} \mathrm{Fe}$ group were counted in a Philips PW 4580 Automatic gamma-counter. When all the unabsorbed Fe had been excreted (i.e.

Table 1. Formulation of semi-synthetic rat diet $(\mathrm{g} / \mathrm{kg}$ diet $)$

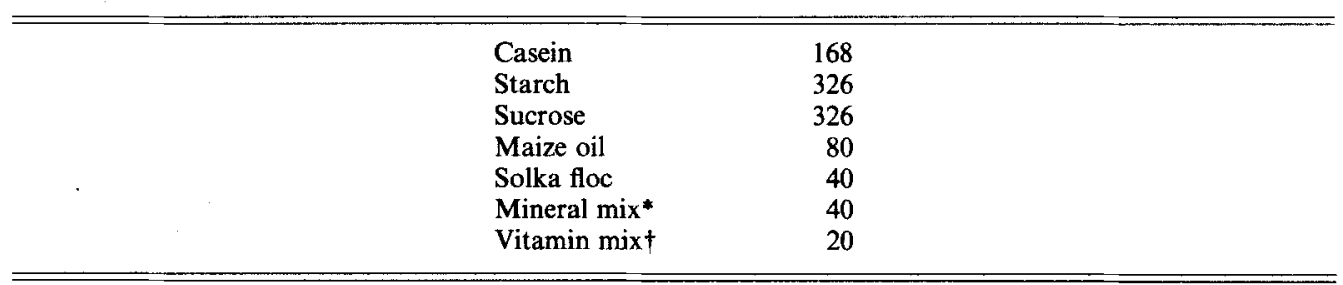

* Contained (g/kg diet): $\mathrm{CaHPO}_{4} 13 \cdot 0, \mathrm{CaCO}_{3} 8 \cdot 2, \mathrm{KCl} 7 \cdot 03, \mathrm{Na}_{2} \mathrm{HPO}_{4} 7 \cdot 4, \mathrm{MgSO}_{4} \cdot \mathrm{H}_{2} \mathrm{O} 4 \cdot 0, \mathrm{MnSO}_{4} \cdot \mathrm{H}_{2} \mathrm{O}$ $0 \cdot 18, \mathrm{ZnCO}_{3} 0 \cdot 10, \mathrm{FeSO}_{4} \cdot 7 \mathrm{H}_{2} \mathrm{O} 0 \cdot 144, \mathrm{CuSO}_{4} 0 \cdot 015, \mathrm{KIO}_{3} 0 \cdot 001$.

$\uparrow$ Contained $(\mathrm{mg} / \mathrm{kg}$ diet): nicotinic acid 60, cyanocobalamin in mannitol 50, calcium D-pantothenate 40 , thiamin hydrochloride 10 , riboflavin 10 , pyridoxine 10 , pteroylmonoglutamic acid 5 , D-biotin 1 , menadione 1 , Rovimix E-25 (Roche, Basle) 300, Rovimix A-500 (Roche) 25, Rovimix A-500/D3 (Roche) 15, choline bitartrate 1800 . 
when daily faecal ${ }^{59} \mathrm{Fe}$ fell to less than $1 \%$ of the administered dose) faeces for the appropriate number of days from each rat in the ${ }^{58} \mathrm{Fe}$ group were bulked, dried at $60^{\circ}$, weighed and ground in a Moulinex grinder. Accurately weighed amounts of approximately $150 \mathrm{mg}$ were put into small plastic containers and the ${ }^{58} \mathrm{Fe}$ content measured by neutron activation analysis (NAA). The total Fe content was also measured by AAS in order to calculate the naturally-occurring amount of ${ }^{58} \mathrm{Fe}$, taking the natural abundance to be $0 \cdot 30 \%$. This value was confirmed by measuring the ${ }^{58} \mathrm{Fe}$ content of faeces from a range of rats of different ages on very different diets. The naturally-occurring ${ }^{58} \mathrm{Fe}$ was subtracted from the total ${ }^{58} \mathrm{Fe}$ content of the faeces to give the enrichment. Fe absorption was calculated by subtracting faecal ${ }^{58} \mathrm{Fe}$ or ${ }^{59} \mathrm{Fe}$ excretion from the administered dose.

\section{$\mathrm{Fe}$ absorption in human subjects from a malted cocoa drink fortified with $\mathrm{FeSO}_{4}$ or $\mathrm{FePO}$ with and without ascorbic acid}

Eleven healthy adult volunteers were selected for the study. The Fe status of the subjects was assessed by measuring haemoglobin using an AO haemoglobinometer (American Optical Instruments), and packed cell volume by the micro-haematocrit method from a finger-prick of blood, since it had been decided to exclude Fe-deficient individuals. The subjects were familiarized with the experimental protocol and the faecal collection technique and were given a number by a third independent person with which to code samples so that all analyses would be carried out blind.

Subjects reported at 09.00 hours on a Monday morning after an overnight fast. They were asked to weigh and record all food eaten on the previous day (Sunday) and then duplicate their diets on the two subsequent Sundays before consuming the test drink. This was an attempt to reduce the well-reported day-to-day intra-individual variation in $\mathrm{Fe}$ absorption.

The malted cocoa drinks were prepared from $20 \mathrm{~g}$ dry powder (containing $1.4 \mathrm{mg}$ naturally-occurring $\mathrm{Fe}$ ) to which hot water was added. In addition to the naturally-occurring Fe they contained the following: drink $1,10 \mathrm{mg} \mathrm{Fe}$ as $\mathrm{FePO}_{4}$ and $20 \mathrm{mg}$ ascorbic acid; drink $2,10 \mathrm{mg} \mathrm{Fe}$ as $\mathrm{FePO}_{4}$; drink 3, 8.8 $\mathrm{mg} \mathrm{Fe}$ as $\mathrm{FeSO}_{4}$. For drinks 1 and 2 a large batch of dried powder was fortified with $\mathrm{FePO}_{4}$ with and without ascorbic acid and packed in sealed cans. Some of the same batch was also sealed in cans without any additions and used for drink 3. The $\mathrm{FeSO}_{4}$ was added to this drink at the last minute, just before consumption.

Each drink was labelled with approximately $1 \mathrm{mg}{ }^{58} \mathrm{Fe}$ before consumption (as $\mathrm{FeCl}_{3}$ in $0.1 \mathrm{M}-\mathrm{HCl}$ ) from ${ }^{58} \mathrm{Fe}$-enriched $\mathrm{Fe}_{2} \mathrm{O}_{3}(66 \%$ enriched). Subjects were given one of the three drinks each week in random order. After finishing the drink they rinsed the cups out with water and drank it to make sure no residue was left in the cup. They abstained from further food or drink for $3 \mathrm{~h}$.

Faecal collections were begun as soon as the drink had been consumed, using plastic bags secured to a collecting frame. Each subject took $500 \mathrm{mg}$ carmine (in two capsules) with their evening meal on the day of the test drink and continued to collect faeces until the carmine had disappeared from the stools plus one further collection. Faecal samples were stored deep-frozen at $-20^{\circ}$.

At the end of the experiment faecal samples for each individual in each collection period were bulked and autoclaved at $121^{\circ}$ for $30 \mathrm{~min}$ to reduce hazards from bacteria and viruses during subsequent handling. The material was then freeze-dried, weighed and ground in a Moulinex grinder and homogenized in a stainless-steel Buhler mill (Camlab, Cambridge). Weighed subsamples were ashed in silica crucibles at $480^{\circ}$ for $48 \mathrm{~h}$ and the weight of ash recorded. Some of the ash was weighed into small plastic vials and the ${ }^{58} \mathrm{Fe}$ content measured by NAA. The remainder was taken up in warm, concentrated $\mathrm{HCl}$, made up to a known volume with distilled water, and the total Fe measured by AAS in a Varian AA6 spectrophotometer (Varian Instruments). 
Samples of drink 1 were analysed for ascorbic acid within hours of opening the tin. Unopened cans were used each week to make up the drinks and the $\mathrm{FeSO}_{4}$ used in drink 3 was added as a solution, made minutes before adding to the drink.

\section{The effect of fasting on Fe absorption in rats}

One hundred male Wistar rats (mean weight $200 \mathrm{~g}$ ) were given a semi-synthetic control diet (Table 1) and trained to meal-feed for $10 \mathrm{~d}$. After an overnight fast they were randomlydivided into seven groups as follows:

\footnotetext{
group 1 , twelve rats were given by intubation $0.1 \mathrm{~g} \mathrm{FePO}_{4}$-fortified malted cocoa drink with added ascorbic acid made up to $1 \mathrm{ml}$ with $0.1 \mathrm{M}-\mathrm{HCl}$, extrinsically labelled with $0.5 \mu \mathrm{Ci}{ }^{59} \mathrm{Fe}$; group 2, twelve rats, as group 1 but without ascorbic acid; group 3, twelve rats, as group 1 but with $\mathrm{FeSO}_{4}$-fortified drink; group 4, eleven rats, $5 \mathrm{~g}$ control diet, followed within $1 \mathrm{~h}$ by the drink given to group 1 ; group 5 , eleven rats, $5 \mathrm{~g}$ control diet, followed within $1 \mathrm{~h}$ by the drink given to group 2 ; group 6 , fourteen rats, $5 \mathrm{~g}$ control diet, followed within $1 \mathrm{~h}$ by the drink given to group 3 ; group 7 , twelve rats, $5 \mathrm{~g}$ control diet, extrinsically labelled with $0.5 \mu \mathrm{Ci}{ }^{59} \mathrm{Fe}$.
}

At $4 \mathrm{~h}$ after dosing, the animals were allowed the control diet ad lib. They were counted in a small animal whole-body counter (Nuclear Enterprises, Edinburgh) immediately after dosing and again at daily intervals until the ${ }^{59} \mathrm{Fe}$ excretion had reached insignificant proportions. Absorption was calculated as the proportion of counts remaining in the animal compared with counts immediately after dosing.

\section{Analytical methods}

NAA. Samples and standards were irradiated for 2 weeks $(70 \mathrm{~h})$ in the Consort reactor $(100 \mathrm{~kW})$ of Imperial College at Silwood Park, Ascot, Berkshire, at a flux of approximately $1.2 \times 10^{16}$ neutrons $/ \mathrm{m}^{2}$ per $\mathrm{s}$. They were allowed to decay for 2 weeks to reduce the activity from short-lived radionuclides and were analysed by gamma-ray spectrometry using a $\mathrm{Ge}(\mathrm{Li})$ semi-conductor detector $(43 \mathrm{ml}$ volume; resolution $1.81 \mathrm{keV}$ at $1332 \mathrm{keV}$ and $8.1 \%$ efficiency) and a Nuclear Data (ND 6600) multi-channel analyser (Nuclear Data, Bourne End, Bucks) with dedicated computer and Fortran programs for spectral analysis. The counting time was $2 \mathrm{~h}$ per sample to give a counting error of $<1 \%$.

$A A S$. Samples to be analysed for Fe were ashed in silica crucibles at $480^{\circ}$ for $48 \mathrm{~h}$, the ash taken up in warm, concentrated $\mathrm{HCl}$ and the solution made up to an appropriate volume. Total $\mathrm{Fe}$ was measured by AAS on a Varian AA6 flame spectrophotometer with background correction.

Ascorbic acid. Dry samples of the malted cocoa powder were extracted with metaphosphoric acid, followed by titration against 2,6-dichlorophenol indophenol (Horwitz, 1975).

$\gamma$-Counting. The ${ }^{59} \mathrm{Fe}$ contents of faeces and blood were measured in a Philips PW 4580 automatic gamma counter with a $75 \times 75 \mathrm{~mm}$ sodium iodide crystal, centre 590 , width 200 , gauge 15 , with a counting efficiency of $13.5 \%$.

Statistical analysis. Differences between groups were tested by unpaired $t$ tests to determine significance (Snednecor \& Cochran, 1973).

ETHICAL CONSIDERATIONS

The protocol for the experiment involving human subjects was approved by the Dunn Ethical Committee, Cambridge. 


\section{RESULTS}

Solubility of $\mathrm{FePO}_{4}$

The $\mathrm{FePO}_{4}$ salt on its own or when added to the malted cocoa was totally soluble in $0 \cdot 1 \mathrm{M}-\mathrm{HCl}$, as was the $\mathrm{FeSO}_{4}$. The $\mathrm{Fe}$ naturally present in the malted cocoa powder was less soluble; the fraction solubilized at $37^{\circ}$ was $0 \cdot 13$ but at $60^{\circ}$ this increased to 0.70 .

\section{Comparison between ${ }^{58} \mathrm{Fe}$ and ${ }^{59} \mathrm{Fe}$ used as extrinsic labels}

Absorption of $\mathrm{Fe}$ from ${ }^{58} \mathrm{Fe}$ - and ${ }^{59} \mathrm{Fe}$-labelled wheat flour and incorporation into blood is shown in Table 2. Absorption was calculated by subtracting faecal excretion from the administered dose. There were no significant differences in absorption between the ${ }^{58} \mathrm{Fe}$ and ${ }^{59} \mathrm{Fe}$ groups or in incorporation into blood. The ${ }^{58} \mathrm{Fe}$ results were adjusted to allow for naturally-occurring ${ }^{58} \mathrm{Fe}$. The published value of $0.30 \%$ natural abundance was confirmed in several faecal samples; the mean value with SE was $0.30(0.01) \%$.

Table 2. Absorption of ${ }^{58} \mathrm{Fe}$ - and ${ }^{59} \mathrm{Fe}$-labelled wheat flour and incorporation into blood (Mean values with their standard errors for twelve rats/group)

\begin{tabular}{|c|c|c|c|c|}
\hline \multirow[b]{2}{*}{ Label } & \multicolumn{2}{|c|}{$\begin{array}{c}\text { Absorption } \\
\text { (proportion of dose) }\end{array}$} & \multicolumn{2}{|c|}{$\begin{array}{c}{ }^{*} \text { Blood level } \\
\text { (proportion of dose) }\end{array}$} \\
\hline & Mean & $\mathbf{S E}$ & Mean & $\mathbf{S E}$ \\
\hline${ }^{58} \mathrm{Fe}$ & 0.514 & 0.033 & 0.322 & 0.020 \\
\hline${ }^{59} \mathrm{Fe}$ & 0.549 & 0.017 & 0.372 & 0.017 \\
\hline
\end{tabular}

* Calculated assuming blood volume to be $7 \cdot 2 \%$ body-weight (Metcoff \& Favour, 1944).

Fe absorption in human subjects from a malted cocoa drink fortified with $\mathrm{FeSO}_{4}$ or $\mathrm{FePO}_{4}$ with and without ascorbic acid

Eleven healthy subjects participated in the study, three females and eight males, mean age 28 years (range 19-40 years). None of the subjects were of abnormal weight or Fe-deficient. Mean haemoglobin (with SE) was $152(2) \mathrm{g} / 1$ and packed cell volume $0.434(0.007)$.

Table 3. Iron intakes $(\mathrm{mg} / \mathrm{d})$ on the day before administration of test drinks, as calculated from food tables (Paul \& Southgate, 1978)

\begin{tabular}{|c|c|c|c|}
\hline \multicolumn{4}{|c|}{ Drink to be given:* } \\
\hline Subject & 1 & 2 & 3 \\
\hline vs & 13.8 & $11 \cdot 4$ & $9 \cdot 0$ \\
\hline SF-T & $10 \cdot 7$ & $9 \cdot 4$ & $10 \cdot 2$ \\
\hline NB & $13 \cdot 7$ & $14 \cdot 3$ & $14 \cdot 2$ \\
\hline RF & 13.4 & $13 \cdot 4$ & $13 \cdot 4$ \\
\hline PJ & 21.9 & $24 \cdot 2$ & $22 \cdot 2$ \\
\hline SS & $10 \cdot 0$ & $10 \cdot 0$ & $10 \cdot 0$ \\
\hline MH & 17.5 & 17.8 & $18 \cdot 8$ \\
\hline SP & $10 \cdot 2$ & $11 \cdot 7$ & $14 \cdot 6$ \\
\hline GE & 12.9 & $13 \cdot 1$ & 11.9 \\
\hline BW & $21 \cdot 5$ & $21 \cdot 7$ & 23.8 \\
\hline MR & $12 \cdot 2$ & 11.8 & 13.0 \\
\hline
\end{tabular}

* For details, see p. 53. 
Table 4. Faecal dry weights $(g)$ and iron content $(\mu g / g$ dry weight) for each collection period

\begin{tabular}{|c|c|c|c|c|c|c|}
\hline \multirow{2}{*}{$\begin{array}{l}\text { Drink given* } \\
\text { Subject }\end{array}$} & \multicolumn{2}{|c|}{1} & \multicolumn{2}{|c|}{2} & \multicolumn{2}{|c|}{3} \\
\hline & Dry wt & $\mathrm{Fe}$ & Dry wt & $\mathrm{Fe}$ & Dry wt & $\mathrm{Fe}$ \\
\hline VS & 199 & 545 & 184 & 441 & 191 & 531 \\
\hline SF-T & 172 & 539 & 115 & 579 & 99 & 406 \\
\hline NB & 133 & 407 & 118 & 441 & 128 & 403 \\
\hline RF & 120 & 523 & 128 & 553 & 128 & 508 \\
\hline PJ & 172 & 474 & 198 & 499 & 142 & 435 \\
\hline SS & 123 & 492 & 110 & 607 & 141 & 446 \\
\hline MH & 130 & 541 & 156 & 485 & 139 & 506 \\
\hline SP & 259 & 629 & 180 & 550 & 213 & 546 \\
\hline GE & 163 & 326 & 176 & 397 & 152 & 399 \\
\hline BW & 132 & 508 & 123 & 520 & 179 & 520 \\
\hline MR & 82 & 646 & 80 & 708 & 119 & 528 \\
\hline
\end{tabular}

*For details, see p. 53.

Table 5. Total ${ }^{58} \mathrm{Fe}$ content of faeces $(\mathrm{mg})$ and proportion of administered dose absorbed from labelled drinks

\begin{tabular}{|c|c|c|c|c|c|c|}
\hline \multirow{2}{*}{$\begin{array}{l}\text { Drink given* } \\
\text { Subject }\end{array}$} & \multicolumn{2}{|c|}{1} & \multicolumn{2}{|c|}{2} & \multicolumn{2}{|c|}{3} \\
\hline & ${ }^{58} \mathrm{Fe}$ & Absorption & ${ }^{58} \mathrm{Fe}$ & Absorption & ${ }^{58} \mathrm{Fe}$ & Absorption \\
\hline VS & $1.095+$ & 0.40 & $1 \cdot 136 \dagger$ & 0.30 & $1 \cdot 101 \ddagger$ & 0.25 \\
\hline SF-T & $1.212 t$ & $0 \cdot 27$ & $1.002+$ & 0.22 & $1.084+$ & $0 \cdot 16$ \\
\hline NB & $1 \cdot 115 t$ & $0 \cdot 26$ & $0.974 \ddagger$ & 0.23 & $1.176 \dagger$ & 0.20 \\
\hline RF & $1.266 \dagger$ & 0.16 & $1 \cdot 167+$ & 0.26 & $1.003+$ & 0.22 \\
\hline PJ & $1.212 \dagger$ & 0.25 & $1.311+$ & 0.21 & $1.025 t$ & 0.21 \\
\hline SS & $1.244 \dagger$ & $0 \cdot 17$ & $1.037 \ddagger$ & 0.21 & $1.225 \ddagger$ & 0.03 \\
\hline MH & 1.048 & 0.21 & $1.083 \uparrow$ & 0.33 & $1.139+$ & 0.28 \\
\hline SP & $1.288 \neq$ & 0.25 & $1.067 \|$ & 0.31 & $1.207 \dagger$ & 0.33 \\
\hline GE & $1.209+$ & 0.18 & $1.353 \dagger$ & 0.11 & $0.976 \dagger$ & 0.38 \\
\hline BW & $0.960 \ddagger$ & 0.29 & $0.198 \dagger$ & 0.22 & $1.198 \dagger$ & 0.28 \\
\hline MR & $1.047 \dagger$ & $0 \cdot 31$ & $0.971 \ddagger$ & 0.25 & $1.253+$ & 0.17 \\
\hline Mean & & 0.25 & & 0.24 & & 0.23 \\
\hline SE & & 0.02 & & 0.02 & & 0.03 \\
\hline
\end{tabular}

*For details, see p. 53.

Extrinsic label: $\uparrow 1.2834 \mathrm{mg}{ }^{58} \mathrm{Fe}, \ddagger 1.0648 \mathrm{mg}{ }^{58} \mathrm{Fe}, \| 1 \cdot 1125 \mathrm{mg}{ }^{58} \mathrm{Fe}$.

Fe intakes by the subjects on the day before the test drinks, calculated from food tables (Paul \& Southgate, 1978) are shown in Table 3. Subjects managed to keep their diets similar or in some cases identical on the Sundays before test drinks.

The faecal dry weights and Fe content are shown in Table 4. The naturally-occurring ${ }^{58} \mathrm{Fe}$ in the faeces was calculated assuming that $0.30 \%$ of total $\mathrm{Fe}$ was ${ }^{58} \mathrm{Fe}$. This value was subtracted from total ${ }^{58} \mathrm{Fe}$ obtained by NAA to give the amount of enrichment and this was expressed as a proportion of the ${ }^{58} \mathrm{Fe}$ dose administered in order to calculate absorption of $\mathrm{Fe}$, as shown in Table 5. There were no significant differences in Fe absorption from the three drinks, i.e. $\mathrm{FePO}_{4}$ plus ascorbic acid, $\mathrm{FePO}_{4}$ or $\mathrm{FeSO}_{4}$. 


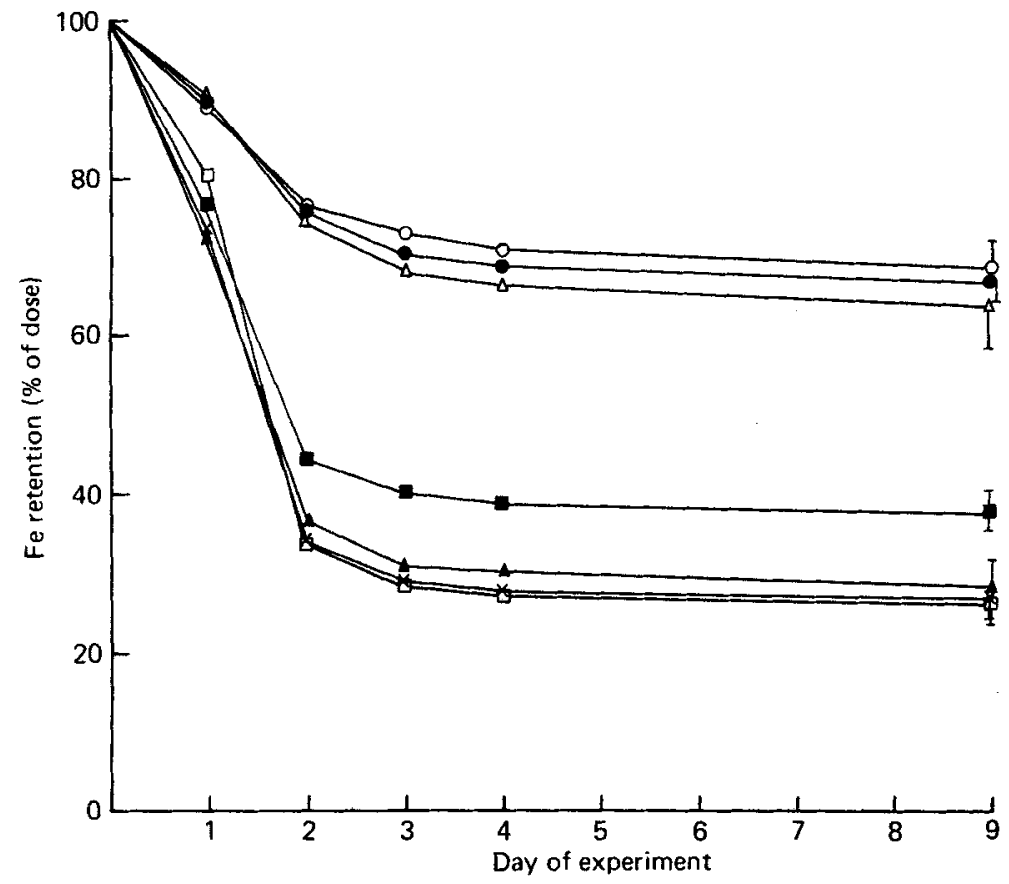

Fig. 1. Iron absorption in rats from a malted cocoa drink given by intubation (a) when fasting: (O), group $1, n 12,0 \cdot 1 \mathrm{~g}$ ferric orthophosphate-fortified malted cocoa drink with added ascorbic acid made up to $1 \mathrm{ml}$ with $0.1 \mathrm{M}$-hydrochloric acid, extrinsically labelled with $0.5 \mu \mathrm{Ci}^{59} \mathrm{Fe} ;(\mathrm{O})$, group $2, n 12$, as group 1 but without ascorbic acid; $(\triangle)$, group $3, n 12$, as group 1 but with ferrous sulphate-fortified drink; (b) post-prandially: (A), group 4, $n 11,5 \mathrm{~g}$ control diet followed within $1 \mathrm{~h}$ by the drink given to group $1 ;(\square)$, group $5, n 11,5 \mathrm{~g}$ control diet, followed within $1 \mathrm{~h}$ by the drink given to group $2 ;(\boldsymbol{Q})$, group 6, $n 14,5$ control diet, followed within $1 \mathrm{~h}$ by the drink given to group 3 ; (c) from a meal alone: $(x)$, group $7, n 12,5 \mathrm{~g}$ control diet, extrinsically labelled with $0.5 \mu \mathrm{Ci}{ }^{58} \mathrm{Fe}$. Points are mean values with their standard errors represented by vertical bars.

\section{The effect of fasting on Fe absorption in rats}

The Fe intakes of each animal from the control diet and fortified malted cocoa drink was as follows:

group 1, $57 \mu \mathrm{g} \mathrm{Fe}$ from $\mathrm{FePO}_{4}$, plus 0.1 $\mathrm{mg}$ ascorbic acid;

group 2, $57 \mu \mathrm{g} \mathrm{Fe}$ from $\mathrm{FePO}_{4}$;

group $3,33 \mu \mathrm{g}$ from $\mathrm{FeSO}_{4}$;

group 4, $200 \mu \mathrm{g} \mathrm{Fe}$ from $\mathrm{FeSO}_{4}$ in control diet, plus $57 \mu \mathrm{g} \mathrm{Fe}$ from $\mathrm{FePO}_{4}$, plus $0.1 \mathrm{mg}$ ascorbic acid;

group 5, $200 \mu \mathrm{g} \mathrm{Fe}$ from $\mathrm{FeSO}_{4}$ in control diet, plus $57 \mu \mathrm{g} \mathrm{Fe}$ from $\mathrm{FePO}_{4}$;

group 6, $200 \mu \mathrm{g} \mathrm{Fe}$ from $\mathrm{FeSO}_{4}$ in control diet, plus $33 \mu \mathrm{g} \mathrm{Fe}$ from added $\mathrm{FeSO}_{4}$;

group 7, $200 \mu \mathrm{g} \mathrm{Fe}$ from $\mathrm{FeSO}_{4}$ in control diet.

The retention of the ${ }^{59} \mathrm{Fe}$-labelled $\mathrm{Fe}$ is shown in Fig. 1. There were no significant differences between $\mathrm{Fe}$ absorption in groups 1,2 and 3 but they were all significantly higher than groups $4,5,6$ and $7(P<0.001)$. Group 6 was significantly higher than groups 5 $(P<0.005)$ and $7(P<0.01)$ but not significantly different from group $4(P<0.1)$.

\section{DISCUSSION}

The use of ${ }^{59} \mathrm{Fe}$ as an extrinsic label for measuring $\mathrm{Fe}$ absorption from foods has been extensively validated. The more recent work with ${ }^{58} \mathrm{Fe}$ suggests that it too can be used as an extrinsic label, which was confirmed by the study with rats in which rats fed ${ }^{58} \mathrm{Fe}-$ or ${ }^{59} \mathrm{Fe}-$ labelled wheat flour exhibited identical absorptive behaviour. 
It has been suggested (Monsen, 1974) that the extrinsic label technique cannot be applied to insoluble $\mathrm{Fe}$, such as $\mathrm{Fe}$ phosphates. Different sources of Fe phosphate exhibit very different solubilities and hence bioavailabilities which may be the reason why there are conflicting reports in the literature concerning the availability of $\mathrm{FePO}_{4}$. For example, Fritz et al. (1975) found that $\mathrm{FePO}_{4}$ had a relative biological value (RBV) of $11 \mathrm{using} \mathrm{FeSO}_{4}$ as the reference standard in rats. Yet in previous work (Fritz et al. 1974) a different sample of $\mathrm{FePO}_{4}$ had a RBV of 44. The authors concluded that the variable utilization of $\mathrm{FePO}_{4}$ was due to differences in $\mathrm{FePO}_{4}$ samples but did not go on to suggest what these differences might be. Rees \& Monsen (1973) found that $\mathrm{FePO}_{4}$ was much less well utilized by rats than $\mathrm{FeSO}_{4}$. They suggested that both chemical and physical characteristics of Fe salts play critical roles in tests of availability especially particle size. Sayers et al. (1974a) showed no difference in $\mathrm{Fe}$ absorption from $\mathrm{FeSO}_{4}$ or $\mathrm{FePO}_{4}$ in human subjects when the salts plus ascorbic acid were added to maize porridge. The Report of the Working Group on Fortification of Salt with Iron (1982) also concluded that $\mathrm{FePO}_{4}$ was reasonably well absorbed since it resulted in significant improvements in haemoglobin levels when added to common salt in large-scale field trials. Harrison et al. (1976) showed that there was a positive correlation between $\mathrm{RBV}$ of $\mathrm{FePO}_{4}$ and solubility in $0 \cdot 1 \mathrm{M}-\mathrm{HCl}$; the most soluble sample $(63.4 \%)$ had a RBV of 46 compared with $\mathrm{FeSO}_{4}$. Thus solubility must be a very important determinant of availability. In the studies described in the present paper the $\mathrm{FePO}_{4}$ was found to be totally soluble in $0.1 \mathrm{M}-\mathrm{HCl}$ and it was concluded that it could therefore be extrinsically-labelled with ${ }^{58} \mathrm{Fe}$ or ${ }^{59} \mathrm{Fe}$.

Absorption by the human subjects of the $\mathrm{FePO}_{4}(0 \cdot 24, \mathrm{SE} 0.02)$ or $\mathrm{FeSO}_{4}(0 \cdot 23, \mathrm{SE} 0.03)$ added to the malted cocoa drink is at first glance surprisingly high. There are two factors that may help explain the high absorption. First, Fe is better absorbed in the fasting state (as is the case in the work reported here) than when given with or shortly after a meal. Brise (1962) showed that absorption in human subjects was reduced by half when an Fe salt was given after a light meal compared with when it was given to fasting subjects. This could be due to $(a)$ chemical interactions of food components on $\mathrm{Fe}$ forming insoluble or undissociated compounds, $(b)$ dilution of the Fe salt with Fe from the meal such that the proportion of $\mathrm{Fe}$ absorbed is reduced, and $(c)$ reduction in Fe concentration by the bulk of the meal and by gastric and intestinal juices. Second, gastric acidity is an important factor. Jacobs et al. (1964) found that Fe absorption in subjects with pernicious anaemia was significantly increased when the Fe salt was given with $0.05 \mathrm{M}-\mathrm{HCl}$ instead of water. It is unlikely that the caffeine levels in the malted cocoa drink $(<50 \mu \mathrm{g} / \mathrm{g}$ dried powder) were high enough to stimulate gastric secretion, although Cohen \& Booth (1975) showed that decaffeinated coffee stimulated gastric secretion to a similar level as ordinary coffee. They suggested that there was a compound in coffee acting in concert with caffeine or a secretagogue acting independently of caffeine. It is possible that the malted cocoa drink given to fasting subjects who were hungry and thirsty had a gastric acid stimulatory effect.

Ascorbic acid had no effect on $\mathrm{Fe}$ absorption from the $\mathrm{FePO}_{4}$-fortified drink at a level of $20 \mathrm{mg}$ per drink, absorption (mean with SE) being $0.25(0.02)$ with ascorbic acid and 0.24 $(0.02)$ without ascorbic acid. Ascorbic acid is often quoted as actively promoting $\mathrm{Fe}$ absorption but the level ingested is important. When Brise \& Hallberg (1962) quantitatively examined the effect of ascorbic acid on ferrous-Fe absorption they found that ascorbic acid had no effect unless given in sufficient amounts, i.e. $200 \mathrm{mg} /$ dose of $30 \mathrm{mg}$ elemental Fe (ascorbic acid: Fe of 21). Sayers et al. $(1974 \mathrm{~b}$ ) found that $60 \mathrm{mg}$ ascorbic acid given with $4 \mathrm{mg}$ elemental $\mathrm{Fe}$ as $\mathrm{FeSO}_{4}$ (ascorbic acid: $\mathrm{Fe}$ of 47 ) and a rice and dhal meal significantly enhanced $\mathrm{Fe}$ absorption, whereas $35 \mathrm{mg}$ ascorbic acid (ascorbic acid: Fe of 27) did not. It is probable that the ascorbic acid:iron value in each system under study determines whether or not the ascorbic acid has an Fe-promoting effect. When the ratio is too low, such as in 
the work described here (ascorbic acid:Fe of 6), there is insufficient ascorbic acid present to chelate the $\mathrm{Fe}$ and keep it available for absorption.

The experiment investigating the effect of fasting on $\mathrm{Fe}$ absorption clearly demonstrated higher $\mathrm{Fe}$ absorption in the fasting state. Absorption was more than twice as great in the fasted animals as in those that had just consumed a meal. In the fasting state there were no differences in availability of $\mathrm{Fe}$ from $\mathrm{FePO}_{4}$ or $\mathrm{FeSO}_{4}$, and the addition of ascorbic acid did not enhance absorption. These findings are in agreement with the human experiment. When, however, the malted cocoa drink was given after a meal, the $\mathrm{Fe}$ from $\mathrm{FeSO}_{4}$ was better absorbed than that from $\mathrm{FePO}_{4}$. Again, ascorbic acid did not improve absorption from $\mathrm{FePO}_{4}$.

It could be argued that the meal contributed a considerable amount of $\mathrm{Fe}$ to the extrinsically-labelled pool, thereby reducing specific activity, with the result that the proportion of labelled $\mathrm{Fe}$ absorbed would be reduced. However, if one considers the most extreme case, i.e. when all the $\mathrm{Fe}$ from the meal remained in the stomach and mixed with the extrinsically-labelled drink, the following calculations can be made to illustrate the theoretical and actual $\mathrm{Fe}$ absorption (expressed as $\mu \mathrm{g} F$ retained):

$\begin{array}{cccc}\begin{array}{c}\text { From } \\ \text { control } \\ \text { diet }\end{array} & \text { From drink } & \begin{array}{c}\text { Control diet } \\ + \text { drink } \\ \text { (theoretical) }\end{array} & \begin{array}{c}\text { Control diet } \\ + \text { drink } \\ \text { (actual) }\end{array} \\ 53 & 39 \text { (group 1) } & 92 & 69 \text { (group 4) } \\ 53 & 38 \text { (group 2) } & 91 & 63 \text { (group 5) } \\ 53 & 21 \text { (group 3) } & 74 & 82 \text { (group 6) }\end{array}$

In practice it is anticipated that some of the control meal would have left the stomach before dosing with labelled drink but the previous calculations show that in the case of $\mathrm{FePO}_{4}$, with and without ascorbic acid, $\mathrm{Fe}$ absorption was reduced when given shortly after a meal whereas the $\mathrm{FeSO}_{4}$ was little affected by the meal. The conclusions to be drawn from this are that factors in the meal have an inhibitory effect on $\mathrm{Fe}$ absorption from $\mathrm{FePO}_{4}$ but not $\mathrm{FeSO}_{4}$, and that the level of ascorbic acid was not high enough to prevent the reduction in $\mathrm{Fe}$ absorption. Ferrous ions are not so readily precipitated as insoluble hydroxides at high $\mathrm{pH}$ as ferric ions. From this experiment it appears that the valency of the $\mathrm{Fe}$ is unimportant when taken on a fasting stomach which may be because of the more acid environment and lack of inhibitory factors derived from dietary components. However, when taken with or shortly after a meal, ferrous-Fe is less likely to be rendered unavailable by chelation with compounds of the meal or precipitation as insoluble ferric hydroxide in the small intestine.

It is concluded from these studies that $\mathrm{FePO}_{4}$, soluble in $0 \cdot 1 \mathrm{M}-\mathrm{HCl}$, was as well absorbed as $\mathrm{FeSO}_{4}$ in fasting human subjects. The addition of ascorbic acid had no effect on availability at an ascorbic acid:iron value of 6 . However, when taken with or shortly after a meal it is anticipated, from the animal experiment, that absorption would significantly fall and that the $\mathrm{FePO}_{4}$ would become less available than $\mathrm{FeSO}_{4}$.

The authors would like to thank Dr J. H. Cummings for advice in designing the human experiment, Mr G. Evans for advice and expert help in microbiological aspects of handling the human faecal material, Ms V. Simmonds and Mrs J. Cooke for help with animal experiments, Mrs W. Nelson and $\mathrm{Mr} \mathbf{A}$. J. Wright for general technical assistance, $\mathrm{Mr}$ M. Gee for the AAS analyses, and all the people who very kindly volunteered to take part in the human study. 


\section{REFERENCES}

Brise, H. (1962). Acta Medica Scandinavica Supplement 376 59, 39-45.

Brise, H. \& Hallberg, L. (1962). Acta Medica Scandinavica, Supplement 376 59, 51-58.

Cohen, S. \& Booth, G. H. (1975). New England Journal of Medicine 30th Oct., 897-899.

Fritz, J. C., Pla, G. W., Harrison, B. N. \& Clark, G. A. (1974). Journal of the Association of Official Analytical Chemists 57, 513-516.

Fritz, J. C., Pla, G. W., Harrison, B. N. \& Clark, G. A. (1975). Journal of the Association of Official Analytical Chemists 58, 902-905.

Harrison, B. N., Pla, G. W., Clark, G. A. \& Fritz, J. C. (1976). Cereal Chemistry 53, $78-84$.

Horwitz, W. (editor) (1975). Official Methods of Analysis of the Association of Official Analytical Chemists, p. 829. Washington DC: Association Official Analytical Chemists.

Jacobs, P., Bothwell, T. \& Charlton, R. W. (1964). Journal of Applied Physiology 19, 187-188.

Janghorbani, M., Ting, B. T. G. \& Young, V. R. (1980). Journal of Nutrition 110, 2190-2197.

Metcoff, J. \& Favour, C. B. (1944). American Journal of Physiology 141, 695-706.

Monsen, E. R. (1974). Journal of Nutrition 104, 1490-1495.

Paul, A. A. \& Southgate, D. A. T. (1978). McCance \& Widdowson's 'The Composition of Foods', MRC Special Report no. 297. London; HM Stationery Office.

Pla, G. W., Harrison, B. N. \& Fritz, J. C. (1973). Journal of the Association of Official Analytical Chemists 56, 1369-1373.

Rees, J. M. \& Monsen, E. R. (1973). Journal of Agricultural and Food Chemistry 21, 913-915.

Report of the Working Group on Fortification of Salt with Iron (1982). American Journal of Clinical Nutrition 35, 1442-1451.

Sayers, M. H., Lynch, S. R., Charlton, R. W., Bothwell, T. H., Walker, R. B. \& Mayet, F. (1974a). British Journal of Haematology 28, 483-495.

Sayers, M. H., Lynch, S. R., Charlton, R. W., Bothwell, T. H., Walder, R. B. \& Mayet, F. (1974b). British Journal of Nutrition 31, 367-375.

Snednecor, G. W. \& Cochran, W. G. (1973). Statistical Methods, 6th ed., p. 100. Iowa: Iowa State University Press. 